\title{
ANALISIS RISIKO KESELAMATAN PEKERJA PT. DAISY MUTIARA SAMUDRA DI DERMAGA 101 DENGAN MENGGUNAKAN METODE HIRARC
}

\author{
WORK SAFETY RISK ANALYSIS PT. DAISY MUTIARA SAMUDRA AT \\ PIER 101 USING HIRARC METHOD
}

\author{
Kencana Verawatia, ${ }^{\text {,* }}$, Nurul Falah ${ }^{\mathrm{b}, 2 \text {, }}$ \\ aProdi D III Transportasi, Fakultas Teknik - Universitas Negeri Jakarta

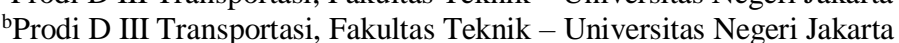 \\ 1*kencanaverawati@unj.ac.id, ${ }^{2}$ nrlfalah23@gmail.com \\ *corresponding e-mail: admind3transportasi@unj.ac.id
}

\begin{abstract}
Analysis of the safety risks of PT. Daisy Mutiara Samudra at Dermaga 101 using the HIRARC method, HIRARC is a tool or method for identifying, assessing and controlling hazards based on activities in each workplace. The results of hazard identification carried out in 3 places on the pier 101 - 102, there are 14 hazards related to safety workers. From the results of identification of the hazard factors, there are 3 factors, namely food factors, facilities factors, human factors. Based on the results of the risk assessment, it is known that the highest percentage of risk level at wharf 101 is moderate risk, which is 58\%. So that the recommendation given by the author to overcome these risks is the addition of facilities and improvement of the worker management system.
\end{abstract}

Keywords: Hazards, Health and safety, Risk Management, HIRARC

\begin{abstract}
ABSTRAK
Analisis risiko keselamatan pekerja PT. Daisy Mutiara Samudra di Dermaga 101 dengan menggunakan metode HIRARC, HIRARC merupakan alat atau metode untuk mengidentifikasi, menilai, dan mengendalikan bahaya berdasarkan kegiatan di setiap tempat kerja Hasil identifikasi bahaya yang dilakukan di 3 tempat di dermaga 101 - 102 terdapat 14 bahaya yang berkaitan dengan keselamatan pekerja. Dari hasil identifikasi faktor terjadinya bahaya terdapat 3 faktor yaitu faktor makanis, faktor fasilitas, faktor manusia. Berdasarkan hasil penilaian resiko, diketahui presentase tertinggi tingkat risiko di dermaga 101 adalah risiko sedang, yaitu sebesar 58\%. Mengatasi risiko tersebut adalah penambahan fasilitas dan perbaikan sistem manajemen pekerja.
\end{abstract}

Kata kunci : Bahaya, Kesehatan dan Keselamatan, Manajemen Risiko, HIRARC 


\section{A. Pendahuluan}

Kecelakaan kerja adalah sesuatu yang tidak terencana, tidak terkontrol dan sesuatu hal yang tidak diperkirakan sebelum nya sehingga menganggu efektivitas kerja seseorang. Kecelakaan kerja adalah sesuatu yang tidak terencana, tidak terkontrol dan sesuatu hal yang tidak diperkirakan sebelum nya sehingga menganggu efektivitas kerja seseorang. Penyebab terjadi nya kecelekaan dibagi menjadi lima, yaitu faktor manusia, alatalat, material, metode kerja, lingkungan hidup, bahan baku, dan faktor lingkungan. (Wijaya, W.S., \& H.C, 2015). Heinrich mengungkapkan terjadinya kecelakaan kerja disebabkan oleh $88 \%$ perilaku tidak aman, 10\% karena kondisi lingkungan yang tidak aman dan 2\% merupakan takdir.

Menurut Data International Labour Organization (ILO) 1 pekerja di dunia meninggal setiap 15 detik karena kecelakaan kerja dan 160 pekerja mengalami sakit akibat kerja. Sedikitnya terjadi 6.000 kasus kecelakaan kerja fatal yang terjadi di Indonesia pada periode tahun 2015 yang menjadikan Indonesia sebagai salah satu negara dengan kecelakaan kerja tertinggi didunia.
Data Angka Kecelakaan Di Indonesia Tahun 2016 - 2019

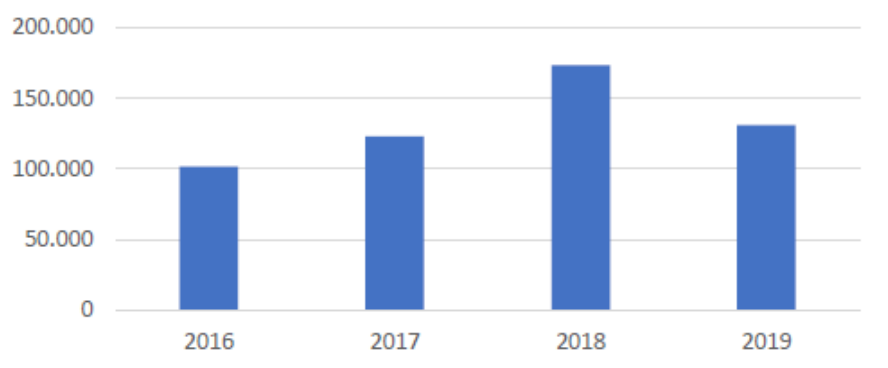

Gambar 1. Data Angka Kecelakaan di Indonesia Tahun 2016-2019

Sumber : BPJS-Ketenagakerjaan

Pada Gambar 1 pada tahun 2016 jumlah kecelakaan kerja sebanyak 101.368 kasus pada tahun 2017 terjadi kenaikan kasus kecelakaan kerja sebanyak 123.041 kasus, sedangkan pada tahun 2018 mengalami kenaikan kasus menjadi 173.415 kasus dan pada tahun 2019 mengalami penurunan kasus menjadi 130.932 kasus.

Untuk mengurangi angka kecelakaan ahli K3 melakukan identifikasi bahaya, penilaian dan pengendalian risiko dan keselamatan kerja. Potensi bahaya (Hazard) terdapat hampir disetiap tempat aktivitas manusia dilakukan, baik dijalan, maupun ditempat kerja. Apabila risiko tersebut tidak dikendalikan dengan benar akan menimbulkan kecelakaan yang berisiko berat.

Hal yang dapat dilakukan untuk menanggulangi bahaya tersebut dengan mancari sumber sumber yang dapat 
menimbulkan bahaya dilingkungan kerja, lalu diadakan identifikasi bahaya. Setelah bahaya teridentifikasi kemudian dievaluasi tingkat risiko bahaya tersebut terhadap tenaga kerja. Dari kegiatan tersebut dapat ditemukan Tindakan untuk pengendalian risiko sampai tingkat aman bagi tenaga kerja, asset perusahaan dan lingkungan.

Untuk meminimalisir adanya kecelakaan kerja pada bagian operasional bongkar muat perlu dilakukan pengendalian. Tindakan yang perlu untuk meminimalisir kecelakan yaitu melakukan analisis potensi bahaya, penilaian risiko dan pengendalian risiko dengan metode Hazard Identification Risk Assesstment and Risk Control (HIRARC).

Adanya bahaya dan risiko pada pekerjaan operasional bongkar muat menjadi alasan dilakukan Hazard Identification Risk Assesstment and Risk Control pada setiap pekerjaan untuk mengetahui bahaya apa saja yang berada di operasional bongkar muat, mengetahui penilaian risiko kecelakaan kerja, dan melakukan pengendalian risiko kecelakaan kerja di operasional bongkar muat PT. Daisy Mutiara Samudra (PT. DMS)

\section{Angka Kecelakaan PT. DMS Tahun 2019}

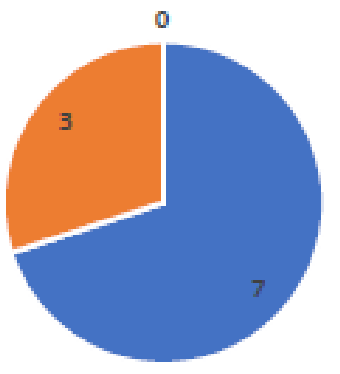

- Kecelakaan Ringan

- Kecelakaan Sedang - Kecelakaan Berat

Gambar 2. Data Angka Kecelakaan PT. DMS

Tahun 2019

Sumber : PT. DMS

Berdasarkan data angka kecelakaan pada tahun 2019 di PT. Daisy Mutiara Samudra yang terdapat di Gambar 1.2 PT. Daisy Mutiara Samudra memiliki 10 kasus kecelakaan yang berkatagorikan ringan dan sedang akibat dari kelalaian manusia maupun dari segi mekanik. Untuk menekan jumlah kecelakaan dan mewujudkan misi perusahaan zero accident selama bekerja perlu dilakukan analisis risiko keselamatan pekerja untuk mengetahui tingkat risiko yang dihadapi pekerja di Dermaga 101. Tujuan Penelitian ini yaitu untuk mengindentifikasi bahaya di dermaga 101 - 102, bagaimana cara menilai dan mengendalikan risiko bahaya yang telah teridentifikasi di PT. DMS.

\section{B. Metode Penelitian}

Penelitian ini merupakan penelitian dengan metode penelitian kualitatif yang bersifat deskriptif. Objek yang diteliti adalah keselamatan 
pekerjaan PT. Daisy Mutiara Samudra pada saat bekerja di Dermaga 101 102 Tanjung Priok. Penelitian ini memfokuskan pada sistem manajemen kesehatan dan kerja dengan upaya mengelola manajemen risiko untuk mencegah terjadinya kecelakan terjadinya kercelakaan yang tidak diinginkan secara terencana dan sistematis dalam suatu sistem yang baik.

\section{Hasil dan Pembahasan}

Identifikasi Bahaya Pada Dermaga 101 $-102$

Berdasarkan proses kerja yang diamati di bagian dermaga 101 - 102, banyak kegiatan pekerja yang beresiko bahaya bagi tubuh.

Bahaya bahaya yang terdapat di bagian lapangan penimbunan sementara antara lain, Forklift menabrak barang atau manusia karena blindspot pada saat merapihkan barang, Forklift kehilangan keseimbangan saat memuat barang, Tidak terdapat area pejalan kaki, Lapangan penimbunan terdapat banyak debu dan oli tercecer, Tidak terdapat alat pemadam ringan saat terjadi kebakaran.

Bahaya yang terjadi di lokasi ini disebabkan oleh tiga faktor. Pertama adalah faktor manusia. Faktor manusia yang menyebabkan terjadinya bahaya adalah kelalaian dan kecerobohan pekerja.

Kedua faktor fasilitas, faktor fasilitas yang menyebabkan terjadinya bahaya adalah kurang nya fasilitas yang terdapat di dermaga 101. Ketiga adalah faktor mekanik, yaitu forklift yang tidak prima dalam menjalankan tugas.

Sedangkan untuk hasil identifikasi bahaya area dermaga antara lain, Sling crane putus, gap antara rel GLC, Tidak ada marka khusus yang mengatur truk di dermaga, bibir dermaga kropos, Banyak pekerja yang menumpang forklift ke area gate in/gate out, pemasangan sling dan ganco.

Bahaya yang terjadi di lokasi ini disebabkan oleh dua faktor, yaitu faktor manusia dan faktor fasilitas. Faktor manusia yang menyebabkan bahaya di area dermaga adalah kelalian dan kecerobohan, sedangkan untuk faktor fasilitas adalah tidak lengkap nya fasilitas penunjang keselamatan yang ada di dermaga 101 .

Sedangkan untuk hasil identifikasi bahaya area gate in/gate out antara lain: Terdapat ceceran oli dan debu, jalanan gate in/out rusak, tidak ada trotoat pemisah pintu gate in/gate out.

Bahaya yang terjadi di lokasi ini disebabkan oleh satu faktor yaitu faktor fasilitas. Fasilitas yang berada di area gate 
in/gate out di dermaga 101 kurang memadai dalam menunjan keselamatan pekerja.

\section{Penilian Bahaya}

Setelah mendapatkan hasil identifikasi bahaya, langkah selanjutnya dalam metode HIRARC adalah penilaian. Pada tahap ini untuk mengetahui tingakatan risiko dari bahaya yang teridentifikasi.

Hasil penilaian untuk area lapangan penimbunan sementara yaitu dari 5 bahaya yang penulis identifikasi terdapat 4 bahaya bertingkat moderate risk dan 1 bahaya bertingkat low risk. Sedangkan hasil penilaian untuk area dermaga yaitu extreme risk, high risk, moderate risk. Sedangkan hasil penilaian untuk area gate in/gate out yaitu: bahaya high risk dan moderate.

\section{Pengendalian Bahaya}

Setelah penilaian risiko selesai, langkah berikutnya adalah menentukan pengendalian risiko. Pengendalian ini bertujuan untuk mengeliminasi atau meminimalisir potensi risiko yang ada. Pengendalian risko lebih diutamakan untuk tingkatan risiko yang tinggi, seperti pada risiko ekstrem (extreme risk) dan risiko tinggi (high risk).
Hasil pengendalian yang disarankan yaitu : membuat area aman khusus pekerja disamping blok timbun, melakukan perawatan forklift berkala, membuat area pejalan kaki bagi pekerja, membersihkan debu dan oli sebelum melakukan bongkar, menyediakan APAR disetiap sisi lapangan penimbunan sementara dan melakukan pengawasan ekstra, mengecek sling crane sebelum melakukan kegiatan bongkar muat, membuat penutup rel GLC agar tinggi celah rel dan dermaga seimbang, membuat marka jalan untuk truk, agar truk tidak berjalan sembarangan dan merugikan pekerja lain, Menambal bibir dermaga dengan mengecor,

Melakukan pengawan ekstra kepada para pekerja dan memberikan teguran atau denda, Pekerja menggunakan sarung tangan, dan melakukan pemasangan sesuai dengan SOP yang dimiliki oleh perusahaan, Petugas harus membersihkan oli yang berceceran agar tidak terjadi kecelakaan kerja, pihak pelabuhan menambal jalan dengan cor-coran kembali atau setidaknya menambal kerusakan yang ada, membangun trotoar untuk pemisah jalan antara yang keluar dengan yang masuk. 
Rekomendasi yang diberikan penulis berdasarkan hasil pelaksanaan identifikasi bahaya di Dermaga 101 - 102 : 1. Penerapan shift kerja yang efektif untuk mengurangi efek risiko, pada tahapan ini digunakan untuk mengurangi tingkat pemaparan bahaya dan kelelahan bekerja terhadap pekerja dengan pembagian waktu kerja dan pemindahan pekerjaan dengan tahapan proses kerja.

2. Membuat prosedur atau instruksi kerja sebelum melakukan pekerjaan dibuat terlebih dahulu semua perencanaan kegiatan setelah mengerti apa yang ada di instruksi kerja dan telah terpenuhi apa yang dibutuhkan untuk selama pekerjaan berlangung, dilangsungkannya pekerjaan yang sesuai dengan instruksi kerja.

3. Memperlengkap alat pelindung diri, APD berguna sebagai sarana pengamanan untuk melindungi diri dari paparan risiko kecelakaan kerja hal ini juga diharapkan untuk mengurangi tingkat risiko pada pekerja.

4. Pengadaan pelatihan mengenai Kesehatan dan keselamatan kerja untuk meningkatkan kesadaran akan pentingnya APD dalam melakukan pekerjaan di dermaga 101.

5. Berkoordinasi dengan pengelola dermaga untuk menambahkan fasilitas yang dinilai kurang yaitu (Road Barrier, Warning Light, Jalur Khusus Pedestrian, APAR, Jalur Khusus Alat Angkut dan Angkat)

\section{Kesimpulan}

1. Identifikasi bahaya yang dilakukan didermaga 101 - 102 dilakukan di area lapangan penimbunan sementara, dermaga, gate in / out. Area lapangan penimbunan memiliki 5 bahaya. Area dermaga memiliki 6 bahaya. Area gate In / Out memiliki 3 bahaya. Berdasarkan hasil identifikasi dan penilaian risiko penulis memberikan rekomendasi perbaikan untuk meningkatkan keselamatan pekerja di PT. Daisy Mutiara Samudra berupa: Penerapan shift kerja yang efektif, Membuat prosedur atau instruksi kerja sebelum melakukan pekerjaan, memperlengkap alat pelindungan diri, Pengadaan pelatihan mengenai kesehatan dan keselamatan kerja, penambahan fasilitas dermaga untuk menunjang keselamatan. 
2. Berdasarkan hasil identifikasi ditemukan empat tingkatan risiko di dermaga 101 - 102. Risiko tersebut adalah 7\% Risiko Ekstrim (Extreme risk), 28\% Risiko tinggi (High risk), 58\% Risiko sedang (Moderate risk), 7\% Risiko rendah (Low risk).

3.

\section{E. Daftar Pustaka}

Hammer, W. (1989). Occupational Safety Management and Engineering. 4ed. New Jersey: Prentince-Hall, Inc.

Harold, K. (2001). Project Management: A System to Planning, Schedulingand Controlling, 7th Edition. New York: John Wiley \& Sons.

Heinrich, H., \& Petersen, D. (1980). Industrial Accident Prevention. McGrawHill Book Company.

Prabu, M. (2001). Manajemen Sumber Daya Manusia. Bandung: PT. Remaja Rosdakarya.

Ramli, S. (2010). Pedoman Praktis Manjemen Risiko Dalam Prespektif K3 OHS Risk Management. Jakarta: Dian Agung .

Suma'mur. (2006). Keselamatan Kerja dan Pencegahan Kecelakaan. Jakarta: PT. Toko Gunung Agung.
Suma'mur, P. (1981). Keselamatan Kerja dan Pencegahan Kecelakaan. Jakarta: PT. Toko Gunung Agung.

Tarwaka. (2008). Keselamatan dan Kesehatan Kerja dalam Manajemen dan Implementasi K3 di Tempat Kerja. Surakarta: Harapan Press.

Wijaya, A., W.S., P., \& H.C, P. (2015). Jurnal Tirta. Vol.3 No.1. Evaluasi Kesehatan dan Keselamatan Kerja dengan Metode HIRARC pada PT. Chareon Pokphand Indonesia, 29-34. 